\title{
Clinical Trials Recruiting Section A new resource for a daunting problem
}

\author{
Steven R. Schwid, MD; and John R. Marler, MD
}

Thanks to advances in basic and translational neuroscience over the last few decades, neurology is gradually shifting from a past of therapeutic nihilism toward an era of experimental therapeutics. While we are still a long way from the goal of a treatment or a trial for every patient, major progress has been made in identifying potentially therapeutic agents based on more thorough understanding of relevant disease processes. The next steps include evaluating the treatment's safety, appropriate dosing, and finally, ensuring efficacy in well-designed controlled trials. Completion of these steps requires establishing patient selection criteria, optimal study designs, and informative primary and secondary endpoints. Investigators often spend years addressing these complex issues during study planning and the iterative processes required to obtain research funding and regulatory approvals. After clearing those hurdles, the next problem is often patient recruitment. This issue of Neurology introduces a new Clinical Trials Recruiting Section designed to help address this concern.

The Association of Clinical Research Professionals (www.acrpnet.org) estimates that $80 \%$ of clinical trials have problems in recruitment that delay or even prevent their completion. Reasons for this include patient concerns about risks and a tendency for investigators to overestimate the availability of appropriate subjects. ${ }^{1,2}$ Disease severity, the availability of other treatment options, race, employment status, and socioeconomic status are all important predictors of the willingness to participate in clinical trials. ${ }^{3,4}$ Even recruitment of healthy controls can be problematic: a study recruiting healthy controls to examine brain-behavior relationships found that only 157 of 1,670 respondents to a newspaper advertisement met all eligibility criteria and were willing to enroll. ${ }^{5}$ These issues are of particular concern for the National Institute for Neurological Disorders and Stroke (NINDS), which currently provides support for over 1,200 clinical research projects addressing 150 different diseases. Approximately 120 of these projects, requiring nearly 10,000 patients per year, are trials to test therapeutic interventions.
Many are experiencing difficulty recruiting subjects. To some extent, enrollment can be improved by making eligibility criteria as open as possible and by minimizing the rigors of study participation. Simplifying inclusion criteria will also improve the generalizability and acceptance of study results. Taking these steps can help increase the proportion of potential candidates who will ultimately enroll in the study, but identifying candidates may still be difficult, especially for studies of rare conditions (e.g., periodic paralysis) or disease subtypes (e.g., primary progressive multiple sclerosis). ${ }^{6}$

Currently, the main sources for study participants are the investigator's clinical practice, referrals from colleagues, conventional advertisement (newspapers, radio, television, and internet), patient registries, and trial registries. Patients in the investigator's practice are often the most accessible, but they may provide a skewed sample if all of the investigators practice in academic settings, limiting generalizability of the study results. ${ }^{4}$ The NINDS along with NIH is currently exploring ways to increase clinical trial involvement by clinicians in all practice settings. The feasibility of enrolling patients from private practice settings has been demonstrated with epilepsy, ${ }^{7}$ but may be more difficult when highly specialized diagnostic techniques and endpoint assessment are required. In many cases, as the testing and data collection performed in a study become more complex, the number of centers that can conduct and eventually use the results of the research decreases.

Conventional advertisements have the potential to identify patients from the broader community, but tend to yield a relatively low percentage of eligible patients, especially when the enrollment criteria are strict. ${ }^{8}$ Patient registries allow volunteers to record basic information about their disease so they can be notified regarding studies for which they may be eligible. Trial registries may work separately (e.g., www. clinicaltrials.gov) or in conjunction with complementary patient registries (e.g., www.centerwatch.com) to provide patients and investigators access to central repositories for studies that are actively enrolling. Both types of registries are often quite incomplete and out of

From Department of Neurology (Dr. Schwid), University of Rochester Medical Center, Rochester, NY; and Clinical Trials Group (Dr. Marler), National Institute of Neurological Disorders and Stroke, National Institutes of Health, Bethesda, MD.

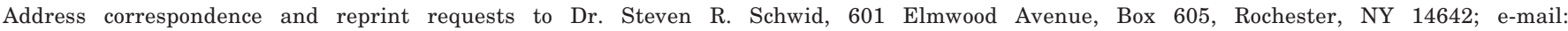
steven_schwid@urmc.rochester.edu

4 Copyright () 2004 by AAN Enterprises, Inc. 
date, however, limiting their usefulness..$^{9}$ None of these methods is effective for studies requiring immediate intervention, where a wide-ranging network must be maintained to instantly alert investigators to potentially eligible patients. Because none of these tools are perfect, investigators need to use a variety of approaches whether the goal is to speed enrollment in general, to ensure that enrolled patients provide optimally generalizable results, or to enhance minority recruitment.

With these issues in mind, Neurology is introducing a new Clinical Trials Recruiting Section in this issue. In the past there have been advertisements for clinical trials scattered throughout the journal. Now these will be listed together in a single section similar to the classifieds, with full page, partial page, and text listings organized by disease. Each notice will include a brief description of the study and its sponsorship as well as contact information for questions and referrals. If desired, announcements may run repeatedly until recruitment is completed. Although the studies listed will not be reviewed or endorsed by the Neurology editorial board or the American Academy of Neurology, they must all obtain Institutional Review Board approval prior to submission. Steven Greenberg, MD, Editor, and Merit Cudkowicz, MD, Co-Editor, will address issues as they arise during the section's introduction and evolution.

Neurology will direct readers to this section with a prominent banner on the cover of the journal, a list- ing in the Table of Contents, and links on the journal home page (www.neurology.com). With a circulation to over 20,000 neurologists and even wider exposure to other professionals and patients through the journal Web site, the Clinical Trials Recruiting Section may be a particularly efficient mechanism to inform both clinicians and patients about research opportunities. As the NINDS examines methods for extending patient recruitment to a broader base of physicians, this section may also help disseminate relevant announcements and links to developing physician networks and patient resources.

\section{References}

1. Lasagna L. Problems in publication of clinical trial methodology. Clin Pharmacol Ther 1979;25:751-753.

2. Williford WO, Bingham SF, Weiss DG, Collins JF, Rains KT, Krol WF The "constant intake rate" assumption in interim recruitment goal methodology for multicenter clinical trials. J Chronic Dis 1987;40:297-307.

3. Schwartz CE, Fox BH. Who says yes? Identifying selection biases in a psychosocial intervention study of multiple sclerosis. Soc Sci Med 1995; 40:359-370.

4. Chang SM, Barker FG, 2nd, Schmidt MH, et al. Clinical trial participation among patients enrolled in the Glioma Outcomes Project. Cancer 2002;94:2681-2687.

5. Shtasel DL, Gur RE, Mozley PD, et al. Volunteers for biomedical research. Recruitment and screening of normal controls. Arch Gen Psychiatry 1991;48:1022-1025.

6. Corrie P, Shaw J, Harris R. Rate limiting factors in recruitment of patients to clinical trials in cancer research: descriptive study. BMJ 2003;327:320-321.

7. Beran RG, Tilley M. Clinical trials of antiepileptic drugs performed in the private practice setting. Epilepsia 1994;35:101-106.

8. Adams J, Silverman M, Musa D, Peele P. Recruiting older adults for clinical trials. Control Clin Trials 1997;18:14-26.

9. Dickersin K, Rennie D. Registering clinical trials. JAMA 2003;290:516523. 


\section{Neurology}

\section{Clinical Trials Recruiting Section: A new resource for a daunting problem Steven R. Schwid and John R. Marler \\ Neurology 2004;63;4-5 \\ DOI 10.1212/01.WNL.0000131905.43402.DA}

This information is current as of July 12, 2004

\section{Updated Information \& Services}

References

Citations

Subspecialty Collections

Permissions \& Licensing

Reprints including high resolution figures, can be found at: http://n.neurology.org/content/63/1/4.full

This article cites 8 articles, 1 of which you can access for free at: http://n.neurology.org/content/63/1/4.full\#ref-list-1

This article has been cited by 1 HighWire-hosted articles: http://n.neurology.org/content/63/1/4.full\#\#otherarticles

This article, along with others on similar topics, appears in the following collection(s):

\section{All Clinical trials}

http://n.neurology.org/cgi/collection/all_clinical_trials

Information about reproducing this article in parts (figures,tables) or in its entirety can be found online at:

http://www.neurology.org/about/about_the_journal\#permissions

Information about ordering reprints can be found online:

http://n.neurology.org/subscribers/advertise

Neurology ${ }^{\circledR}$ is the official journal of the American Academy of Neurology. Published continuously since 1951, it is now a weekly with 48 issues per year. Copyright . All rights reserved. Print ISSN: 0028-3878. Online ISSN: 1526-632X.

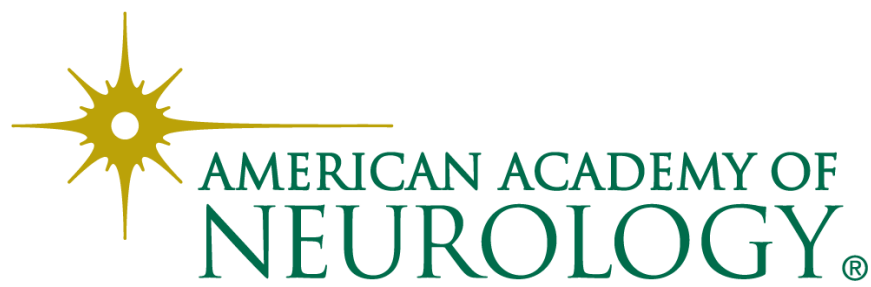

